UDC: 616-085.816:616-005:616.831]-053.31

DOI: 10.15587/2519-4798.2020.219263

\title{
EFFECT OF NON-INVASIVE VENTILATION ON CENTRAL AND BRAIN HEMODYNAMICS IN TERM NEWBORN INFANTS WITH HYPOXIC - ISCHEMIC ENCEPHALOPATHY
}

\section{E. Klevakina, I. Anikin, O. Mykhalchuk}

The aim of the research. To study the effect of invasive and non-invasive lung ventilation in full-term infants with moderate and severe HIE on cerebral perfusion and central hemodynamics. Materials and methods To study the effect of non - invasive lung ventilation on central hemodynamics and cerebral perfusion, 60 infants with moderate and severe YIE were examined, thirty of them had early tracheal extubation 72 hours after birth and were transferred to non-invasive nasal lung ventilation with intermittent positive pressure (NIPPV), another 30 new-borns formed a comparison group. They had a traditional MV.

Results No differences were found between the mean blood pressure and heart rate in the newborn core and comparison group, both during the first day of stay and during the fourth day, when the core group infants were extubated and transferred to NIPPV, but the mean BP level increased significantly after the core group infants were transferred to NIPPV, compared to the values of this indicator during the first day $(p<0.05)$.

The study of central hemodynamics indices in the new-born infants of the main group within a day after extubation and transfer to NIPPV did not reveal any differences in comparison with the new-born comparison groups. Stroke volume, heart index and left ventricular ejection fraction did not differ in the main group and comparison group.

When studying the effect of non-invasive lung ventilation on brain perfusion, no reliable differences between the study groups were also found.

Conclusions. No statistical difference was found between HI and EF in the main group and the comparison group, respectively. Non-invasive ventilation in NIPPV mode does not affect cerebral perfusion indices compared to conventional ventilation NIPPV and can be used in intensive care of new-borns with HIE

Keywords: hypoxic ischemic encephalopathy, new-born, non-invasive ventilation, hemodynamics, cerebral perfusion

Copyright (C) 2020, E. Klevakina, I. Anikin, O. Mykhalchuk.

This is an open access article under the CC BY license (http://creativecommons.org/licenses/by/4.0).

\section{Introduction}

Hypoxic-ischemic encephalopathy (HIE) remains one of the most important medical and social problems of modern neonatology and neonatal intensive care, because it is due to these patients that the number of children with disabilities is increasing. The frequency of this pathology is 2-3 cases per 1000 full-term new-borns in developed countries and up to 26 cases per 1000 full-term newborns - in underdeveloped countries [1].

In intensive care of new-borns with moderate and severe HIE, the leading place is occupied by respiratory support, which allows to achieve a correspondence between the delivery of oxygen and energy substrates and the metabolic needs of the brain $[2,3]$. The main, effective way to improve the results of treatment of children with HIE - is the procedure of therapeutic hypothermia [1]. According to most authors, artificial ventilation (AV) should be performed in neonates with moderate and severe HIE throughout the period of therapeutic hypothermia and the early period after warming, generally 3-5 days [4-6].

HIE is often associated with increased pulmonary hypertension, meconium aspiration syndrome, and unstable central hemodynamics. The main purpose of the correction of central hemodynamics is the prevention and treatment of secondary disorders of cerebral perfusion [7].

In addition, HIE is accompanied by cerebral reperfusion and excessive oxidative stress [8]. Hypothermia causes a decrease in metabolic rate, while reducing oxygen consumption $\left(\mathrm{O}_{2}\right)$ and carbon dioxide $\left(\mathrm{CO}_{2}\right)$ production [9]. Despite numerous evidences of harmful effects of hypocapnia, it is difficult to achieve normocapnia in these patients $[10,11]$.

Usually, new-borns use artificial ventilation with pressure control in the airways - pressure control ventilation (PC). The main advantage of this mode is the uniform distribution of gas in inhomogeneous lungs [12]. A significant disadvantage of this regime is the lack of control over tidal volume, which can lead to significant fluctuations in $\mathrm{CO}_{2}$ levels, which in turn negatively affects cerebral perfusion [13, 14]. Volume control ventilation (VC), although devoid of this disadvantage, is associated in neonates with a high percentage of ventilator-associated complications, barotrauma, and air leakage syndrome $[15,16]$.

The aim of the work. To study the effect of invasive and non-invasive artificial ventilation in full-term infants with moderate and severe HIE on cerebral perfusion and central hemodynamics.

\section{Materials and methods}

A prospective, cohort, randomized study was conducted in which $60(100.0 \%)$ infants born between 38 and 42 weeks of gestation were treated in the Department of Anesthesiology and Neonatal Intensive Care (DANIC) of the Municipal Non-Commercial Enterprise 
"Regional Clinical Children's Hospital" of the Zaporizhia Regional Council in the period from September 2017 to May 2020 on HIE II and III degree on the Sarnat scale (modified by Hill A., Volpe JJ, 1994). The study involved infants who required $\mathrm{AV}$ due to the presence of respiratory disorders.

The work was carried out in accordance with the World Medical Code of Ethics

Association (Declaration of Helsinki) and approved by the Bioethics Commission of Zaporizhia State Medical University, the conclusion report №1 from 16.01.2018. The parents of all patients included in the study gave written informed consent to participate in the study.

The study involved neonates in the acute period of HIE, with a score on the scale Sarnat II-III, age $\leq 72$ hours from birth.

Children with signs of intrauterine growth retardation, sepsis, heart defects and less than 37 weeks of gestation were not included in the study.

All neonates required primary resuscitation and received care and intensive care, which included early use of total therapeutic hypothermia (target rectal temperature $-33.5{ }^{\circ} \mathrm{C}$ ), for 72 hours (onset time $2.5 \pm$ \pm 0.56 hours).

To assess the severity of HIE on admission, the Sarnat scale was used in the modification of A. Hill, J. J. Volpe (1994) and the Thompson scale.

In order to diagnose and treat lung lesions, all newborns underwent chest radiography on admission to the department and thereafter after treatment every 5 days.

To study the characteristics of different types of pulmonary ventilation on the condition of infants and compare the types of respiratory support, formed 2 groups: the main group which included $30(50.0 \%)$ newborns who were 72 hours after birth with performed tracheal extubation and transferred to non-invasive nasal ventilation with intermittent positive pressure (NIPPV) by Avea (CareFusion ${ }^{\circledR}$, USA) and SLE 6000 (SLE®, UK) using silicone long nasopharyngeal cannulas (VYGON®), EU), if during their installation there were technical difficulties associated with the narrowness of the nasal passages, then installed short oxygen nasal cannulas (Neotech RAM Cannula ${ }^{\circledR}$, USA). The comparison group consisted of $30(50.00 \%)$ children who underwent invasive auxiliary flow-controlled pulmonary ventilation with airway pressure control through an intubation tube until the level of consciousness was restored, there was no seizure and a regular pattern of selfbreathing was established.

Stages of research: 1 stage - at the time of admission to the department; stage $2-72$ hours after birth; stage 3 - on the 4 th day after birth, stage 4 - a day after transferring the child to self-breathing.

At the start of treatment, for the first 72 hours of life, all infants underwent forced or assisted flowcontrolled pulmonary ventilation with airway pressure control (P - SIMV).

At all stages of the study were evaluated the indicators of systemic hemodynamics: left ventricle (LV) end-diastolic (EDD) and end-systolic (ESD) dimensions, left ventricle (LV) end-diastolic (EDV) and end-systolic
(ESV) volume, stroke volume (SV). The LV ejection fraction was calculated automatically. In order to objectify the above indicators, indices corresponding to the surface area of the body were calculated. The calculation of the body surface area $\left(\mathrm{BSA}, \mathrm{m}^{2}\right)$ of infants was performed according to the formula:

$$
\operatorname{BSA}\left(\mathrm{m}^{2}\right)=(0.05 \times \mathrm{kg})+0.05,
$$

where $\mathrm{kg}$ - weight of the child. Cerebral blood flow was examined in the anterior cerebral artery (ACA): measured systolic blood flow rate $-\mathrm{V}_{\max }(\mathrm{cm} / \mathrm{sec}$.), the average blood flow rate during the cardiac cycle $-\mathrm{V}_{\text {mean }}$ ( $\mathrm{cm} / \mathrm{sec}$.), diastolic blood flow rate $-\mathrm{V}_{\min }(\mathrm{cm} / \mathrm{sec}$.). In the automatic mode was determined PI - Gosling pulsation cerebral blood flow index and resistance index (RI), as the most used in neonatology. Doppler mapping of cardiac activity was performed on an ultrasound scanner "Medisson 8000" SA and a portable ultrasound scanner "Medisson Pico" (made in Korea), a microconvex sensor with a frequency of 2-4 MHz. The examination was more often performed from the subcostal position due to the increased airiness of the lung tissue, or from the standard parasternal position.

Statistical processing of the obtained results was performed using software packages STATISTICA 13.0, TIBCO Software inc. (License JPZ804I382130ARCN10-J) and MICROSOFT EXCEL 2013 (License 00331-1000000001-AA404).

Data in the text and tables are presented in the form of $\mathrm{M} \pm \mathrm{SD}$ (arithmetic mean \pm standard deviation) in the case of normal distribution of the studied trait and $\mathrm{Me}$ (Q1; Q3) (median of the sample indicating the upper (75\%) and lower (25\%) quartiles) - with a distribution that is different from normal.

To assess the significance of the difference between the absolute values of the mean values, nonparametric methods of statistical analysis were used: MannWhitney test (U) for unrelated groups and Wilcoxon sign test (T) for related groups. The criterion $\mathrm{p}<0.05$ was accepted as significant in all tests.

\section{Research results}

The main and comparison groups did not differ statistically in gestational age, body weight and age of infants on admission to the hospital.

No significant difference was found between the groups by gender structure: the share of boys in the main and comparison groups was $23(76.7 \%)$ and $16(53.3 \%)$ patients, respectively, girls - $7(23.3 \%)$ and $14(46,7 \%)$ respectively; $\mathrm{p}>0.05$.

In the main group, $20(66.7 \%)$ babies were born by vaginal delivery, and $10(33.3 \%)$ by cesarean section. In the comparison group - 17 (56.7 \%) and $13(43.3 \%)$, respectively; $\mathrm{p}>0.05$.

The severity of asphyxia at birth is indicated by the score on the Apgar scale at the 1st minute: in the main group was $7.0(3.0 ; 7.0)$ points, in the comparison group - $7.0(5.0 ; 7.0)$ points; $p>0.05$. At the 5 th minute $7.0(5.7 ; 9.0)$ and $7.0(5.0 ; 7.0)$ points, respectively, $\mathrm{p}>0.05$ (Table 1). 
Analysis of the main characteristics of the main group and the comparison group

\begin{tabular}{|l|c|c|c|}
\hline \multicolumn{1}{|c|}{ Indicator } & Main group $(\mathrm{n}=30)$ & Comparison group $(\mathrm{n}=30)$ & $\mathrm{p}$ \\
\hline Gestation period, weeks & $39.3 \pm 1.5$ & $38.9 \pm 1.3$ & $>0.05$ \\
\hline Body weight, kg & $3.6 \pm 0.6$ & $3.3 \pm 0.5$ & $>0.05$ \\
\hline $\begin{array}{l}\text { Age of infants on admission to the hospital, } \\
\text { hours }\end{array}$ & $15.0(9.0 ; 28.0)$ & $10.5(5.0 ; 32.0)$ & $>0.05$ \\
\hline Apgar score 1 min., points & $7.0(3.0 ; 7.0)$ & $6.0(3.0 ; 7.0)$ & $>0.05$ \\
\hline Apgar score 5 min., points & $7.0(5.7 ; 9.0)$ & $7.0(5.0 ; 7.0)$ & $>0.05$ \\
\hline Severity of HIE on the Sarnat scale, points & $2.0(2.0 ; 2.0)$ & $2.0(2.0 ; 3.0)$ & $>0.05$ \\
\hline Therapeutic hypothermia, $\mathrm{n}(\%)$ & $6(20.0 \%)$ & $11(36.6)$ & $>0.05$ \\
\hline Boys, $\mathrm{n}(\%)$ & $23(76.7 \%)$ & $16(53.3 \%)$ & $>0.05$ \\
\hline Girls, $\mathrm{n}(\%)$ & $7(23.3 \%)$ & $14(46.7 \%)$ & \\
\hline Vaginal delivery, $\mathrm{n}(\%)$ & $20(66.7 \%)$ & $17(56.7 \%)$ & $>0.05$ \\
\hline Cesarean section, $\mathrm{n}(\%)$ & $10(33.3 \%)$ & $13(43.3 \%)$ & \\
\hline Meconium aspiration, $\mathrm{n}(\%)$ & $3(10.0 \%)$ & $5(16.6 \%)$ & $>0.05$ \\
\hline
\end{tabular}

Clinical diagnosis of HIE manifestations from the cardiovascular system consisted of measuring heart rate (HR) and non-invasive blood pressure (BP) in the extremities. Comparison of blood pressure and heart rate in the groups are presented in Table 2.

At the time of admission to the hospital in newborns of both the main and comparison groups, the average BP in the analysis of measurements did not differ significantly and corresponded to the age norm of 76.0 (69.5; 84.0) $\mathrm{mm} \mathrm{Hg}$ and $76.50(71.00 ; 93.0) \mathrm{mm} \mathrm{Hg}$; $\mathrm{p}>0.05$, respectively. After transferring the children of the main group to $\mathrm{nAV}$, the level of mean BP significantly increased by $82.0(75.5 ; 89.0) \mathrm{mm} \mathrm{Hg}$ in comparison with the values of this indicator on the first day of hospital stay $76.0(69.5 ; 84.0) \mathrm{mm} \mathrm{Hg} ; \mathrm{p}<0.05$.

Although the level of mean BP was within the acceptable range for a given age and gestational age, it should be noted that inotropic dopamine support was given to children of both groups to stabilize hemodynamic disturbances. In the main group, at the time of admission $10(33.3 \%)$ new-borns received hemodynamic support at a dose of 5.0 $(5.0 ; 10.0) \mu \mathrm{g} / \mathrm{kg} / \mathrm{min}$, in the study group - $16(53.0 \%)$ in dose $5.0(5.0 ; 7.5) \mu \mathrm{g} / \mathrm{kg} / \mathrm{h} ; \mathrm{p}>0.05$. At day 4 of life, after switching to $\mathrm{nAV}$, only $1(3.3 \%)$ child of the main group required the introduction of sympathomimetics, while in the comparison group $3(10.0 \%)$.

The heart rate did not differ significantly and corresponded to the age norm at the time of admission in children of the main group - $130.0(116.0 ; 143.0)$ per minute and the comparison group - 127.5 (117.0; 143.0) per minute, $p>0.05$. There was also no difference between this indicator for the 4th day of observation: in the main group it was - $138.0(122.7 ; 148.2)$ per minute, and in the comparison group - $133.5(127.0 ; 146.0)$ per minute, $\mathrm{p}>0.05$.

HR remained within the age norm after extubation on the transfer of children of the main group to nAV and amounted to $138.0(122.7 ; 148.2)$ per minute and did not differ from this figure on the first day of hospital stay $130.0(116,0 ; 143.0)$ per minute; $p>0.05$.

Given the existing data on the negative impact of forced mechanical ventilation on the central and cerebral blood flow, we suggested an improvement in cardiac output and a decrease in cerebral vascular resistance after extubation of infants [17]. The study of central hemodynamics and cerebral perfusion in infants of the main group one day after extubation and transfer to noninvasive ventilation, did not reveal the expected differences compared with new-borns of the control group. SV in the main group and the comparison group were $4.9 \pm 1.1 \mathrm{ml}$ and $4.6 \pm 1.2 \mathrm{ml}$, respectively; $\mathrm{p}>0.05$. Accordingly, there is no statistical difference between SI in the main group and the comparison group, which amounted to $2886.3(2101.9 ; 3268.8) \mathrm{ml} / \mathrm{m}^{2}$ and $2581.7(2094.3 ; 3681.8) \mathrm{ml} / \mathrm{m}^{2}$, respectively; $\mathrm{p}>0.05$ (Table 2).

Table 2

Indicators of systemic blood pressure and heart rate in new-borns in the main group and the comparison group

\begin{tabular}{|c|c|c|c|}
\hline Studied indicator & Main group $(\mathrm{n}=30)$ & Comparison group $(\mathrm{n}=30)$ & $\mathrm{p}$ \\
\hline \multicolumn{5}{|c|}{ Primary respiratory support (up to 72 hours) } \\
\hline Heart rate in 1 minute & $130.0(116.0 ; 143.0)$ & $127.5(117.0 ; 143.0)$ & $>0.05$ \\
\hline BP average, $(\mathrm{mm} \mathrm{Hg})$ & $76.0(69.5 ; 84.0)$ & $76.5(71.0 ; 93.0)$ & $>0.05$ \\
\hline Heart rate in 1 minute & Secondary respiratory support (after 72 hours) & $>0.05$ \\
\hline BP average, $(\mathrm{mm} \mathrm{Hg})$ & $138.0(122.7 ; 148.2)$ & $133.5(127.0 ; 146.0)$ & $>0.05$ \\
\hline
\end{tabular}

The study of the left ventricular ejection fraction revealed the absence of a significant deviation of this indicator relative to the comparison group $-75(68.3 ; 80.0) \%$ and 75 $(66.6 ; 80.0) \% ; p>0.05$, respectively.

When analyzing the effect of non-invasive lung ventilation on cerebral blood flow, no significant differences between the study groups were also found. It should be noted that the value of IR was used for the analysis, as the most used in neonatology, due to the fact that its value does not depend on the angle of the sensor and the operation of the operator.

In the Table 4 showed the indicators of maximum systolic velocity in ACA, maximum diastolic velocity in ACA, resistance index and pulsation index against the background of NIPPV application during one day. 
Comparison of central hemodynamics and cerebral perfusion in the study groups on the background of the use of NIPPV and traditional AV in the day after extubation

\begin{tabular}{|c|c|c|c|}
\hline Studied indicators & Main group $(\mathrm{n}=30)$ & Comparison group $(\mathrm{n}=30)$ & $\mathrm{p}$ \\
\hline LV EDD, $\mathrm{cm}$ & $1.5 \pm 0.2$ & $1.5 \pm 0.1$ & $>0.05$ \\
\hline LV ESD, $\mathrm{cm}$ & $0.9 \pm 0.1$ & $0.9 \pm 0.1$ & $>0.05$ \\
\hline LV EDV, cm & $7.3 \pm 1.2$ & $7.0 \pm 1.7$ & $>0.05$ \\
\hline LV ESV, cm & $2.0 \pm 0.4$ & $1.9 \pm 0.7$ & $>0.05$ \\
\hline LV SV, $\mathrm{ml}$ & $4.9 \pm 1.1$ & $4.6 \pm 1.2$ & $>0.05$ \\
\hline CI, $\mathrm{ml} / \mathrm{m}^{2}$ & $2886.3(2101.9 ; 326.8)$ & $2581.7(2094.3 ; 3681.8)$ & $>0.05$ \\
\hline LV EF, \% & $75(68.3 ; 80.0)$ & $75(66.6 ; 80.0)$ & $>0.05$ \\
\hline IR, ACA & $0.64(0.5 ; 0.7)$ & $0.69(0.61 ; 0.7)$ & $>0.05$ \\
\hline IP, ACA & $1.12(0.8 ; 1.3)$ & $1.28(1.0 ; 1.4)$ & $>0.05$ \\
\hline
\end{tabular}

Table 4

The effect of NIPPV on cerebral perfusion in the main group $(n=30)$ after extubation

\begin{tabular}{|c|c|c|c|}
\hline Studied indicator & 3rd day & 4th day & $\mathrm{p}$ \\
\hline $\mathrm{V}_{\max } \mathrm{cm} / \mathrm{sec}$. & $43.1(35.3 ; 52.7)$ & $50.2(1.3 ; 56.2)$ & $<0.05$ \\
\hline $\mathrm{V} \mathrm{min} \mathrm{cm} / \mathrm{sec}$. & $13.5(8.0 ; 21.5)$ & $18.3(12.0 ; 22.6)$ & $<0.05$ \\
\hline $\mathrm{IR}, \mathrm{ACA}$ & $0.6(0.6 ; 0.7)$ & $0.6(0.5 ; 0.7)$ & $<0.05$ \\
\hline $\mathrm{IP}, \mathrm{ACA}$ & $1.2(1.0 ; 1.5)$ & $1.1(0.8 ; 1.3)$ & $<0.05$ \\
\hline
\end{tabular}

Analysis of the data given in tab. 3 shows a significant decrease in IR $(\mathrm{p}<0.05)$ and IR $(\mathrm{p}<0.05)$ one day after the use of nAV in the NIPPV regimen in the neonates of the main group. This suggests that the NIPPV mode has a less negative effect on cerebral circulation than the AV mode in the SIMV and A/C modes.

\section{Discussion}

D. Surkov and co-authors (2014) in their prospective, observational, multicenter, longitudinal, cohort study, which studied the effect of respiratory support and its parameters on cerebral perfusion and central hemodynamics in newborns with severe and moderate HIE, concluded that types of AV do not affect cerebral perfusion. No correlations were found between clinical indicators of HIE assessment and mechanical ventilation, cerebral hemodynamics. The authors claim that conducting AV in this category of patients is safe, but this study concerned only traditional AV through an intubation tube [18].

In our study, on the 5th day of life in infants of both groups there was a restoration of neurological status, the level of consciousness, which in both groups was assessed as lethargy. Dynamic score on the Thompson scale, revealed a decrease in the total number of points to $5(4.0 ; 6.0)$ in the main group, and to $7(5.0 ; 8.0)$ in the group of children on prolonged intubation, which had a statistical difference $<0.05$. Thus, the median assessment of Thompson's neurological status was different, and was better in children in the non-invasive ventilation group. This result can be justified by the proposed method, which helped to reduce vascular resistance detected by Doppler in the main group.

Chang HY et al. (2016) also studied the hemodynamic effects of NIPPV in a prospective study of clinically stable but preterm infants, and believe that noninvasive AV does not affect systemic hemodynamics and cerebral blood flow, but note that for a more detailed study of hemodynamic effects of this type of AV larger studies using NIPPV over a longer period of time are needed [19].

Our study presents treatment outcomes from a small sample of patients, which may somewhat limit the ability to detect intergroup differences. This problem can be solved by conducting additional multicenter randomized controlled trials, calculating the correlations between the obtained indicators.

Study limitations. The limitations of the study are related to a small sample of patients.

Prospects for further research is to further develop the study of the effectiveness and safety of the use of non-invasive nasal ventilation with intermittent positive pressure in full-term infants with HIE.

\section{Conclusions}

1. In the main group, whose children were on traditional AV and in the comparison group, in which early extubation was performed, and the transition to noninvasive AV, no statistical differences were found between SI ( $>>0.05)$ and EF ( $p>0.05)$.

2. Non-invasive AV in NIPPV mode does not affect cerebral perfusion rates of IR and IP compared to traditional AV.

Given that the study did not reveal a negative effect of non-invasive nasal ventilation with intermittent positive pressure (NIPPV) on systemic hemodynamics and cerebral perfusion in full-term infants with moderate and severe HIE, it can be argued that NIPPV can be used in this neonatal category as a secondary respiratory support after early tracheal extubation due to less invasiveness.

\section{Conflict of interests}

The authors declare that they have no conflicts of interest. 


\section{References}

1. Douglas-Escobar, M., Weiss, M. (2015). Hypoxic-ischemic encephalopathy: A review for the clinician. JAMA Pediatr, 169, 397-403. doi: http://doi.org/10.1001/jamapediatrics.2014.3269

2. Lantos, L., Berenyi, A., Morley, C., Somogyvari, Z., Belteki, G. (2020). Volume guarantee ventilation in neonates treated with hypothermia for hypoxic-ischemic encephalopathy during interhospital transport. Journal of Perinatology. doi: http://doi.org/10.1038/s41372-020-00823-8

3. Foster, J. P., Buckmaster, A., Sinclair, L., Lees, S., Guaran, R. (2015). Nasal continuous positive airway pressure (nCPAP) for term neonates with respiratory distress. Cochrane Database of Systematic Reviews, 11. doi: http://doi.org/10.1002/14651858.cd011962

4. Lopez Laporte, M. A., Wang, H., Sanon, P.-N., Barbosa Vargas, S., Maluorni, J., Rampakakis, E., Wintermark, P. (2017). Association between hypocapnia and ventilation during the first days of life and brain injury in asphyxiated newborns treated with hypothermia. The Journal of Maternal-Fetal \& Neonatal Medicine, 32 (8), 1312-1320. doi: http://doi.org/10.1080/14767058.2017.1404980

5. Thyagarajan, B., Baral, V., Gunda, R., Hart, D., Leppard, L., Vollmer, B. (2017). Parental perceptions of hypothermia treatment for neonatal hypoxic-ischaemic encephalopathy. The Journal of Maternal-Fetal \& Neonatal Medicine, 31 (19), $2527-2533$. doi: http://doi.org/10.1080/14767058.2017.1346074

6. Verma, P., Kalraiya, A. (2017). Respiratory compliance of newborns after birth and their short-term outcomes. International Journal of Contemporary Pediatrics, 4 (2), 620-624. doi: http://doi.org/10.18203/2349-3291.ijcp20170720

7. Rainaldi, M. A., Perlman, J. M. (2016). Pathophysiology of Birth Asphyxia. Clinics in Perinatology, 43 (3), 409-422. doi: http://doi.org/10.1016/j.clp.2016.04.002

8. Zhao, M., Zhu, P., Fujino, M., Zhuang, J., Guo, H., Sheikh, I. (2016). Oxidative Stress in Hypoxic-Ischemic Encephalopathy: Molecular Mechanisms and Therapeutic Strategies. International Journal of Molecular Sciences, 17 (12), 2078. doi: http://doi.org/10.3390/ijms17122078

9. Yenari, M. A., Han, H. S. (2012). Neuroprotective mechanisms of hypothermia in brain ischaemia. Nature Reviews Neuroscience, 13 (4), 267-278. doi: http://doi.org/10.1038/nrn3174

10. Lingappan, K., Kaiser, J. R., Srinivasan, C., Gunn, A. J. (2016). Relationship between PCO2 and unfavorable outcome in infants with moderate-to-severe hypoxic ischemic encephalopathy. Pediatric Research, 80 (2), 204-208. doi: http://doi.org/10.1038/pr.2016.62

11. Pfister, R. H., Bingham, P., Edwards, E. M., Horbar, J. D., Kenny, M. J., Inder, T. et. al. (2012). The Vermont oxford neonatal encephalopathy registry: rationale, methods, and initial results. BMC Pediatrics, 12 (1). doi: http://doi.org/10.1186/14712431-12-84

12. Goldsmith, J., Karotkin, E., Suresh, G., Keszler, M. (2017). Assisted Ventilation of the Neonate. Evidence-Based Approach to Newborn Respiratory Care. Elsevier, 640.

13. Brainerd, T. L. (2012). Assisted Ventilation of the NeonateAssisted Ventilation of the Neonate. JAMA, 307 (22). doi: http://doi.org/10.1001/jama.307.22.2437-a

14. Pappas, A., Shankaran, S., Laptook, A. R., Langer, J. C., Bara, R., Ehrenkranz, R. A. et. al. (2011). Hypocarbia and Adverse Outcome in Neonatal Hypoxic-Ischemic Encephalopathy. The Journal of Pediatrics, 158 (5), 752-758. doi: http://doi.org/10.1016/j.jpeds.2010.10.019

15. Bancalari, E., Claure, N. (2015). Advances in respiratory support for high risk newborn infants. Maternal Health, Neonatology and Perinatology, 1 (1). doi: http://doi.org/10.1186/s40748-015-0014-5

16. Gupta, S., Janakiraman, S. (2018). Volume ventilation in neonates. Paediatrics and Child Health, 28 (1), 1-5. doi: http://doi.org/10.1016/j.paed.2017.09.004

17. Donn, S. M., Sinha, S. K. (2006). Manual of neonatal respiratory care. Elsevier, 580

18. Surkov, D. N., Kapustina, O. G., Ivanov, D. O. (2014). Influence of positive pressure ventilation on cerebral status of newborns in acute period of hypoxic-ischemic encephalopathy. Vestnik sovremennoi klinicheskoi meditsiny, 6 (7), 46-55.

19. Chang, H.-Y., Cheng, K.-S., Lung, H.-L., Li, S.-T., Lin, C.-Y., Lee, H.-C. et. al. (2016). Hemodynamic Effects of Nasal Intermittent Positive Pressure Ventilation in Preterm Infants. Medicine, 95 (6), e2780. doi: http://doi.org/10.1097/md.0000000000002780

Received date 20.08.2020

Accepted date 18.09.2020

Published date 30.11.2020

Elena Klevakina, Postgraduate student, Department of Pediatric Surgery and Anesthesiology,Zaporizhzhia State Medical University, Maiakovskoho ave., 26, Zaporizhzhia, Ukraine, 69035

E-mail: elenaklevakina29@gmail.com

Ivan Anikin, PhD, Associate Professor, Department of Pediatric Surgery and Anesthesiology, Zaporizhzhia State Medical University, Maiakovskoho ave., 26, Zaporizhzhia, Ukraine, 69035

E-mail: anikin1974@ukr.net

Olexandr Mykhalchuk, Ultrasonic Doctor, Zaporizhzhia Regional Clinical Children's Hospital, Sobornyi ave., 70, Zaporizhzhia, Ukraine, 69063

E-mail: mihalzpua1979@gmail.com 